\title{
Effect of Fabric Layers on the Relationship between Fabric Constructional Parameters and Percentage Reflectance Values of Polyester Fabrics
}

\author{
Mine Akgun, Behcet Becerir, and Halil Rifat Alpay \\ Textile Engineering Department, Faculty of Engineering, Uludag University, Gorukle, 16059 Bursa, Turkey \\ Correspondence should be addressed to Behcet Becerir; becerir@uludag.edu.tr
}

Received 20 May 2014; Revised 30 September 2014; Accepted 30 September 2014; Published 16 October 2014

Academic Editor: Phillip W. Gibson

Copyright (C) 2014 Mine Akgun et al. This is an open access article distributed under the Creative Commons Attribution License, which permits unrestricted use, distribution, and reproduction in any medium, provided the original work is properly cited.

\begin{abstract}
This paper focused on the assessment of the relation between constructional properties and percentage reflectance values of fabrics woven from polyester yarns through fabric layer numbers. Reflectance measurements were conducted on pretreated but undyed fabric samples at five different fabric layers. Twelve polyester fabrics having different constructional parameters were used and fabrics differed from each other by their weft yarn densities, weave patterns, and weft yarn filament fineness. Warp yarn properties (type, count, and density) were the same at all the fabrics. Percentage reflectance values of the fabrics changed according to yarn density, weave pattern, and filament fineness in accordance with fabric layer numbers during reflectance measurement. Percentage reflectance values gradually increased as fabric layer numbers increased. The highest reflectance values were obtained at 16 layers of fabric. The effects of single constructional parameters on reflectance values disappeared as fabric layer numbers increased. Percentage reflectance values were analyzed according to ANOVA (Analysis of Variance) and statistical results revealed the cross relations obtained. Light-trap phenomenon was discussed according to reflectance characteristics of woven fabrics.
\end{abstract}

\section{Introduction}

Color measurements on opaque surfaces (textile fabrics) are made by measuring the percentage reflectance of surfaces and the measured reflectance values are transferred to color computing software for the determination of color coordinates and other color related properties, that is, whiteness. Whiteness of textiles is an important aspect which is considered in daily life. White textiles are usually preferred by customers especially in summer because of comfort reasons. Also white, being an achromatic color, has a physiological effect on human sensation.

Fibers which are used in textile fabric production for domestic purposes have intrinsic colors of their own mainly given at the production stage. Polyester fibers, being synthetic ones, are usually produced in white color from matt to bright by the usage of delustering agents such as titanium dioxide. The white color of fabrics produced from polyester yarns could be changed to a whiter shade by wet treatments using textile auxiliary agents or by applying fluorescent whitening agents (FWAs) to fabrics. Depending on the domestic usage, polyester fabrics could be used without any application of FWAs.

When the constructional properties of fabrics are considered in relation with their color, it is recognized that the visual color could change according to the effect of constructional properties on appearance of fabric samples. Under these circum-stances appearance properties of fabric structures become important.

Appearance is a variable of the perceptual world detected by the visual system. Characterization of appearance, new approaches to appearance definition, past considerations, and appearance related subjects were well documented and referenced by Lozano and Caivano $[1,2]$. According to Lozano and Caivano, appearance can be divided into three components: color, cesia, and spatial variation or spatiality. Also color is divided into three parts: lightness, chroma, and hue. The last two variables form what we call chromaticity. Lightness is related to cesia when it is converted to luminosity, also giving place luminous transmittance or reflectance. Color 
will include whiteness and yellowing and is related to optical power spectral properties of the stimulus detected by observers [1].

In most cases color is an important factor in the production of the material and is often vital to the commercial success of the product. The color of an object depends on many factors, such as lighting (illumination), size of sample, and background and surrounding colors. Much more importantly, color is a subjective phenomenon and depends on the observer $[3,4]$.

When a beam of light encounters the surface of an object, a small portion of it is reflected and does not penetrate. The actual amount of reflected light is dependent upon the smoothness of the surface, the refractive index of the material, and the angle at which the beam strikes the surface. The light striking an object will be affected by interaction with the object in a number of different ways. The resulting light distributions give us our expressions of what that object looks like. The diffuse reflection caused by the scattering of light within a material, where no selective absorption by dyes and pigments is involved, causes a white appearance. In the majority of objects specular (shiny) reflection, diffuse reflection by scattering, and absorption operate which result in the color and appearance of the objects [5].

Steen and Dupont [6] researched the reflectance measurements of the highly structured white textiles. White can be defined as an aspect of color corresponding to a high luminosity and an absence of the hue. The impression of whiteness of a surface implies two conditions: a diffuse reflectance which is as flat as possible (achromatic) and the highest possible reflectance values. A white textile can rarely be compared to a sheet of white paper or a flat surface which is painted white. A textile surface is often highly structured, permeable to light, and composed of different materials. Highly structured surfaces (lace and embroidery in the lingerie sector) can mean that difficulties arise when measuring the color or whiteness of such a material.

There is also another phenomenon linked to structured white textiles, known as the light-trap rule. A so-called "flat textile" is structured with more or less regularly spaced hollows and bumps. This regularity allows good colorimetric measurements to be made in certain conditions (i.e., maximum aperture, sample layered until it is opaque, and multiple measurements). These simple rules mean that it is possible to limit the differences between two measurements of the same flat textile article. Nevertheless, each hollow between the yarns or fibers is a light trap which darkens the color of the fabric [6].

It was concluded by Steen and Dupont that the lighter a textile was, the greater the influence of its physical structure on the color would be and the less tolerant they would be in accepting it. With regard to whites, they observed lighttrap phenomenon for a large number of different structures. The magnitude of the phenomena was linked to the physical structure of the textiles. Steen and Dupont showed that the distribution of the measurements of a white textile sample gets more dispersed as the sample gets more structured.

Relations between the physical structure of textile surfaces and light reflectance through fiber fineness were researched by Kobsa et al. and Rubin et al. $[7,8]$ in detail. The greater amount of the reflected light which appeared from textile surfaces containing microfiber (microdenier) yarns was attributed to the peculiar properties of these fibers during production, to their physical forms, and to their physical existence and settlement in textile structures. The light-trap phenomenon was discussed from another aspect related with microfiber properties.

The relation between fabric cover factors and light reflectance of polyester fabrics was researched by Akgun et al. [9]. A novel formula was proposed and its results were tested in accordance with reflectance measurements.

Many research works [1, 2, 6-12] showed that physical structure of fabric samples strongly affects reflectance measurements and color results obtained. When reporting about color of a fabric surface, the physical structure of fabric surface surely plays an important role in obtaining the results. The complex phenomena of color when altered with physical structure implied that color could be considered as a subgroup of appearance. More strict rules might be needed in color measurement to avoid the results to be dependent more on physical structure. Also the term of "appearance measurement" could be proposed to measure the reflectance properties of the highly structured textiles.

This paper focused on the assessment of the relation among constructional properties and percentage reflectance values of fabrics woven from polyester yarns through fabric layer numbers. The relation phenomenon between physical structure and percentage reflectance values was considered from the view point of fabric layers of woven fabrics. Percentage reflectance values of fabrics changed according to the yarn density, weave pattern, and filament fineness in accordance with fabric layer numbers during reflectance measurement. Cross relations among fabric constructional properties and fabric reflectance values were obtained.

\section{Materials and Methods}

2.1. Materials. Fabrics consist of weft yarns having the same yarn count but different filament numbers (filament counts), and yarn densities were used in the experimental part. Also different weave patterns were considered to assess the relations among fabric percentage reflectance values and properties of fibers, yarns, and fabrics through fabric layer numbers.

Twelve polyester woven fabrics with different constructional parameters were used. Fabrics were woven under controlled mill conditions in order to obtain exact constructional properties. After weaving, woven fabrics were pretreated (washed with $2 \mathrm{~g} / \mathrm{L}$ nonionic agent at $60^{\circ} \mathrm{C}$ for 30 minutes and later stentered without tension at $180^{\circ} \mathrm{C}$ for 60 seconds) under mill conditions and prepared for reflectance measurement in the laboratory. Constructional parameters of the fabrics were given in Table 1. Twill and sateen fabrics were weft faced ones. Fibers of the yarns had round cross-sectional shapes and they were semidull fibers (commercially available from a spinning mill in Bursa). Warp yarn properties and warp densities were the same for all the fabrics under consideration. Weft yarn properties differed from each other in terms of weft yarn densities and weft yarn filament fineness. 
TABLE 1: Constructional parameters of the fabrics.

\begin{tabular}{|c|c|c|c|c|}
\hline Fabric weave & Warp count [denier/filament] & Warp density [thread/cm] & Weft count [denier/filament] & Weft density [thread/cm] \\
\hline \multirow{2}{*}{ Plain } & \multirow{2}{*}{$70 / 36$} & \multirow{2}{*}{60} & \multirow{2}{*}{$100 / 36$} & 15 \\
\hline & & & & 20 \\
\hline \multirow{2}{*}{ Plain } & \multirow{2}{*}{$70 / 36$} & \multirow{2}{*}{60} & \multirow{2}{*}{$100 / 144$} & 15 \\
\hline & & & & 20 \\
\hline \multirow{2}{*}{$1 / 2$ twill } & \multirow{2}{*}{$70 / 36$} & \multirow{2}{*}{60} & \multirow{2}{*}{$100 / 36$} & 15 \\
\hline & & & & 20 \\
\hline \multirow{2}{*}{$1 / 2$ twill } & \multirow{2}{*}{$70 / 36$} & \multirow{2}{*}{60} & \multirow{2}{*}{$100 / 144$} & 15 \\
\hline & & & & 20 \\
\hline \multirow{2}{*}{$1 / 5$ sateen } & \multirow{2}{*}{$70 / 36$} & \multirow{2}{*}{60} & \multirow{2}{*}{$100 / 36$} & 15 \\
\hline & & & & 20 \\
\hline \multirow{2}{*}{$1 / 5$ sateen } & \multirow{2}{*}{$70 / 36$} & \multirow{2}{*}{60} & \multirow{2}{*}{$100 / 144$} & 15 \\
\hline & & & & 20 \\
\hline
\end{tabular}

Reflectance measurements were made on ready-to-dye white polyester fabric samples. Two different weft yarns with 100-denier yarn count were used composed of 36 and 144 filaments, respectively. 100/36 (yarn denier/filament number) yarn could be considered as polyester yarn with conventional fiber fineness ( 2.7 denier per filament) and 100/144 (yarn denier/filament number) yarn could be considered as polyester yarn with microfiber (microdenier) fiber fineness $(\sim 0.60 \mathrm{dpf})$. The fabrics were produced at two weft densities,'namely, 15 and 20 threads $/ \mathrm{cm}$. These weft densities were recalled in "Results and Discussions" part as 15- and 20thread weft yarn density.

2.2. Methods. Percentage reflectance values of the samples were measured on a Macbeth Reflectance Spectrophotometer (MS 2020+) between 400-700 nm (at $20 \mathrm{~nm}$ intervals) under a D65/10 illuminant and in SCI (Specular Component Included) mode. Percentage reflectance values were recorded according to AATCC Evaluation Procedure 6 [13].

Samples were prepared as four replicas for reflectance measurement. Four reflectance measurements were made on each replica with a sample rotation of $90^{\circ}$ and percentage reflectance of a sample was calculated by using total sixteen measurements. Reflectance measurements of the replicas were made at different fabric layers (from the single layer up to 2, 4, 8 and 16 layers) on the achromatic black background (black background color coordinates; average \%R: 4.88; average $K / S$ : 9.27; $L^{*}: 26.3 ; a^{*}: 0.04 ; b^{*}:-0.29 ; C^{*}: 0.29 ; h^{\circ}$ : 277.69).

\section{Results and Discussions}

Percentage reflectance values of fabric samples according to increasing fabric layer numbers were presented in Figures 116 for the evaluation of effects of yarn densities, weave patterns, and filament fineness on reflectance properties. Fabric samples were laid on an achromatic black background during reflectance measurements in order to absorb all illumination which passed through the samples. The usage of calibration tile (as a white background) disabled the reflectance results to be clearly obtained.

A general consideration of all the figures showed that percentage reflectance values obtained at fabrics with single fabric layer gradually decreased as the wavelength increased. The reason could be the single layer which could not reflect all the light which fell upon it during illumination because of the black background. The insufficient cover of single layer fabrics could not reflect the illuminating light and some part of the light was primarily absorbed by the black background. The D65/10 illumination is high at the blue region but it is considerably low in the red region of the spectrum. The illumination distribution during measurement could have let the reflectance distribution be obtained in such a characteristic manner in single layers. Also the comparatively higher reflectance values of 20-thread weft yarn density at single fabric layer supported the results. The intrinsic light reflection properties of the single layer fabrics were obtained.

A general similarity of all the figures was that percentage reflectance values gradually increased as fabric layer numbers and wavelengths increased. Percentage reflectancewavelength distribution of the one and more layered white fabrics showed the same characteristics of white surfaces as given by McDonald [3]. Percentage reflectance values of 16 layers of fabrics were a little higher than those obtained at 8 -layer fabrics. Distinct differences in percentage reflectance values were obtained among single and up to 16-layer fabrics.

As pointed in AATCC [13] technical manual most textile samples are nonopaque to some extent and it is advisable to layer the material until light no longer penetrates through layers. The required thickness of any given specimen can be determined by measuring it with increasing layers until no further change in the reflectance data is observed. The results of experimental part showed that minimum number of the layers in reflectance measurement of white polyester fabric samples must be 8 or 16 fabric layers. However, cross relations were obtained because of the light-trap phenomenon of the fabric surfaces. The results and discussions given below indicated the reflectance behavior of 16 layers of fabric otherwise pointed. 


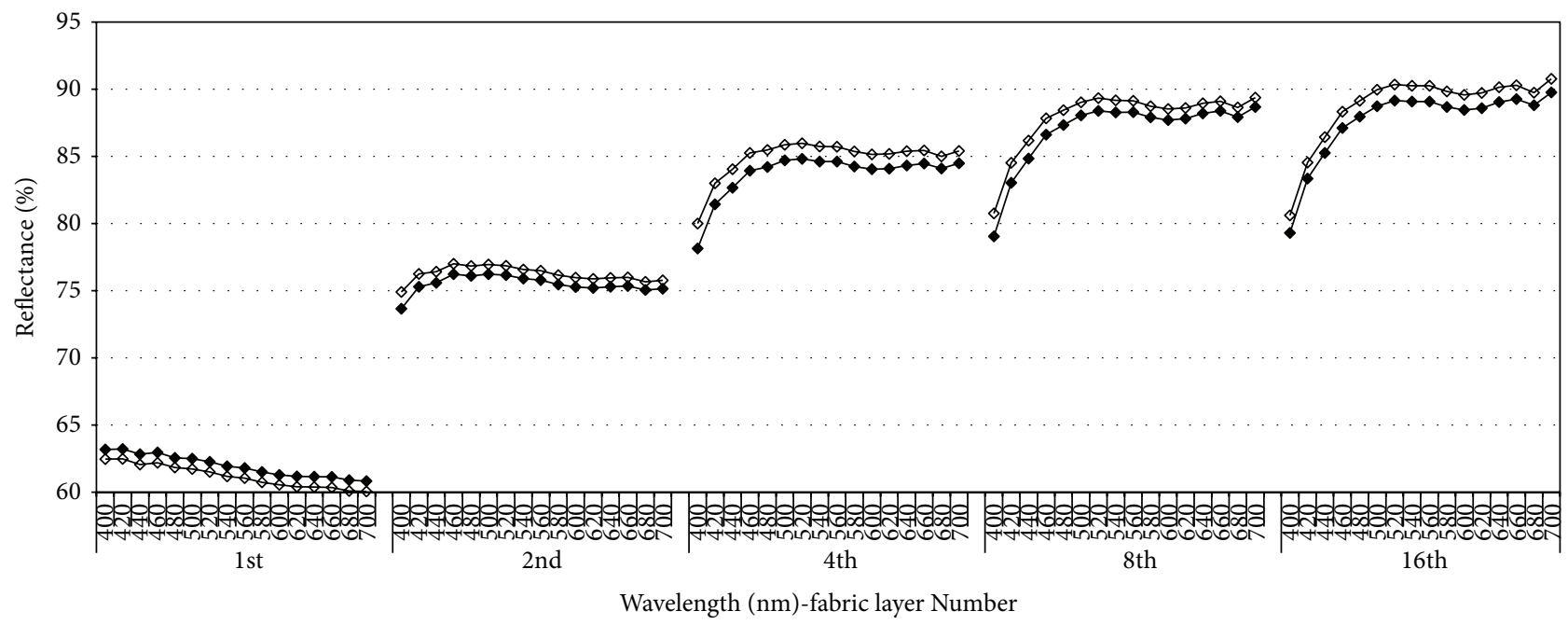

15 threads $/ \mathrm{cm}$

. 20 threads $/ \mathrm{cm}$

FIGURE 1: Percentage reflectances according to weft density (yarn count: 100/36 and weave pattern: plain).

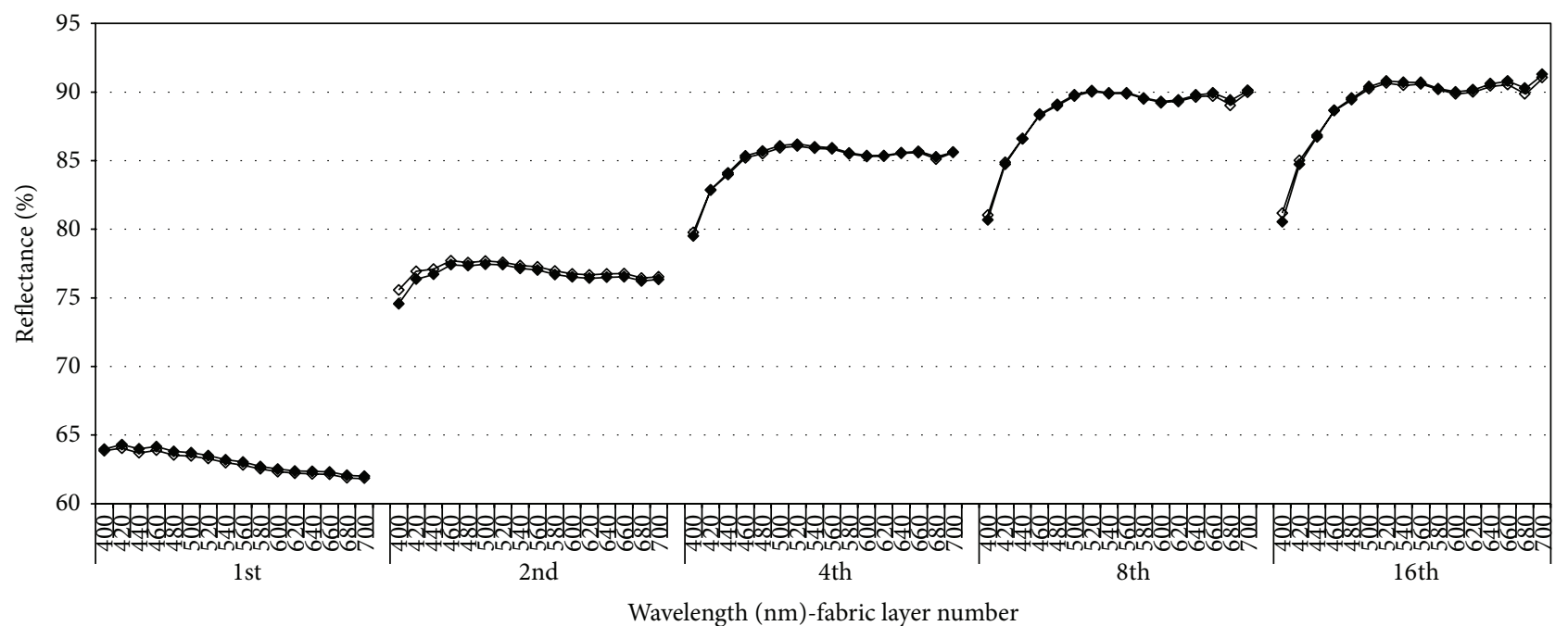

$\rightarrow 15$ threads $/ \mathrm{cm}$

$\rightarrow 20$ threads $/ \mathrm{cm}$

FIGURE 2: Percentage reflectances according to weft density (yarn count: 100/36 and weave pattern: 1/2 twill).

3.1. Effect of Yarn Densities on Percentage Reflectance. Effects of yarn densities on percentage reflectance values of plain, twill, and sateen fabrics were presented in Figures 1-3 for $100 / 36$ yarns and in Figures 4-6 for 100/144 yarns. In Figures $1-3$, reflectance values of samples woven with conventional fibers were presented. Percentage reflectance values of sateen weave were slightly higher than those of plain and twill weaves at single, 2, and 4 fabric layers. Also percentage reflectance values of plain and sateen weaves woven with 15-thread weft yarn density were higher than that of samples woven with 20-thread weft yarn density as the fabric layer numbers increased. The difference between percentage reflectance values increased as fabric layers increased. Percentage reflectance values of twill fabrics presented in Figure 2 were the same for both weft yarn densities (15- and 20-thread weft yarn density).

In Figures 4-6, reflectance values of samples woven with microfibers were presented. In Figure 4, percentage reflectance values of samples woven in plain weave were almost the same for the two weft yarn densities. However, percentage reflectance values of samples woven in twill and sateen weaves were much different from each other especially 


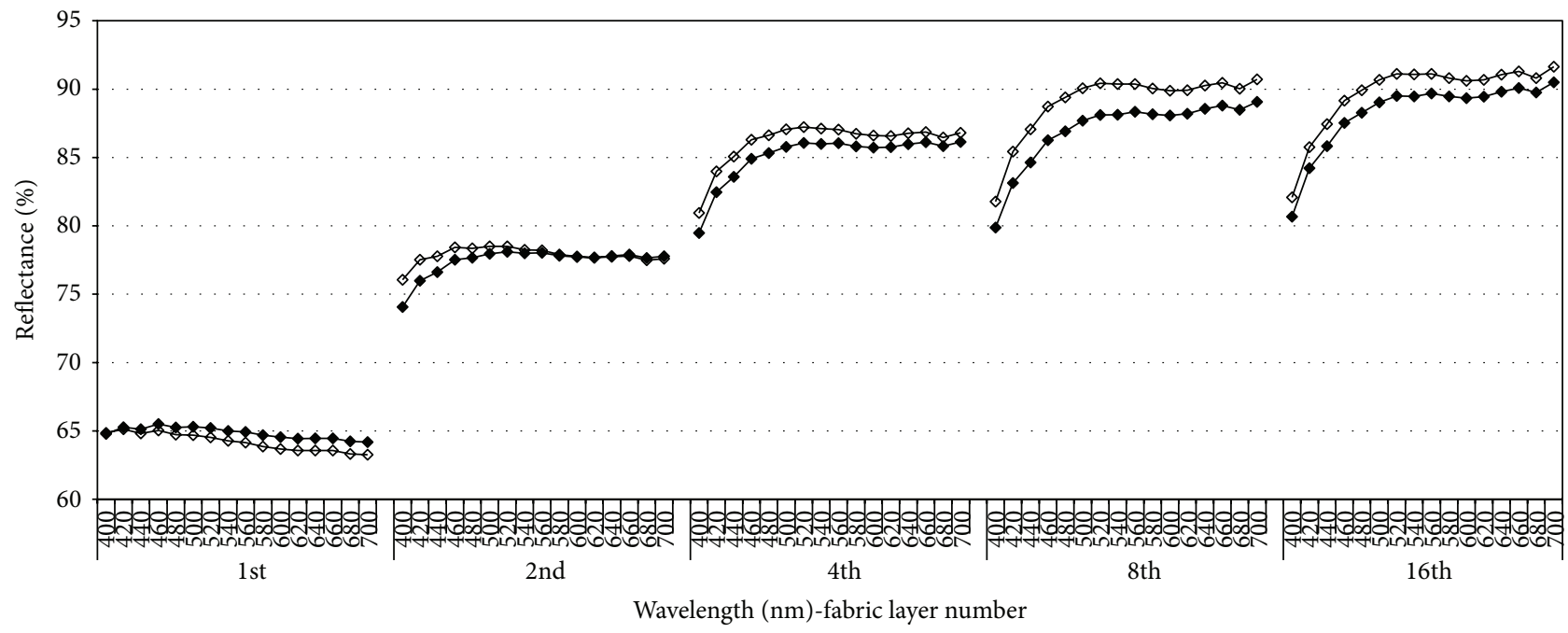

$\rightarrow 15$ threads $/ \mathrm{cm}$

$\rightarrow 20$ threads $/ \mathrm{cm}$

FIgURE 3: Percentage reflectances according to weft density (yarn count: 100/36 and weave pattern: 1/5 sateen).

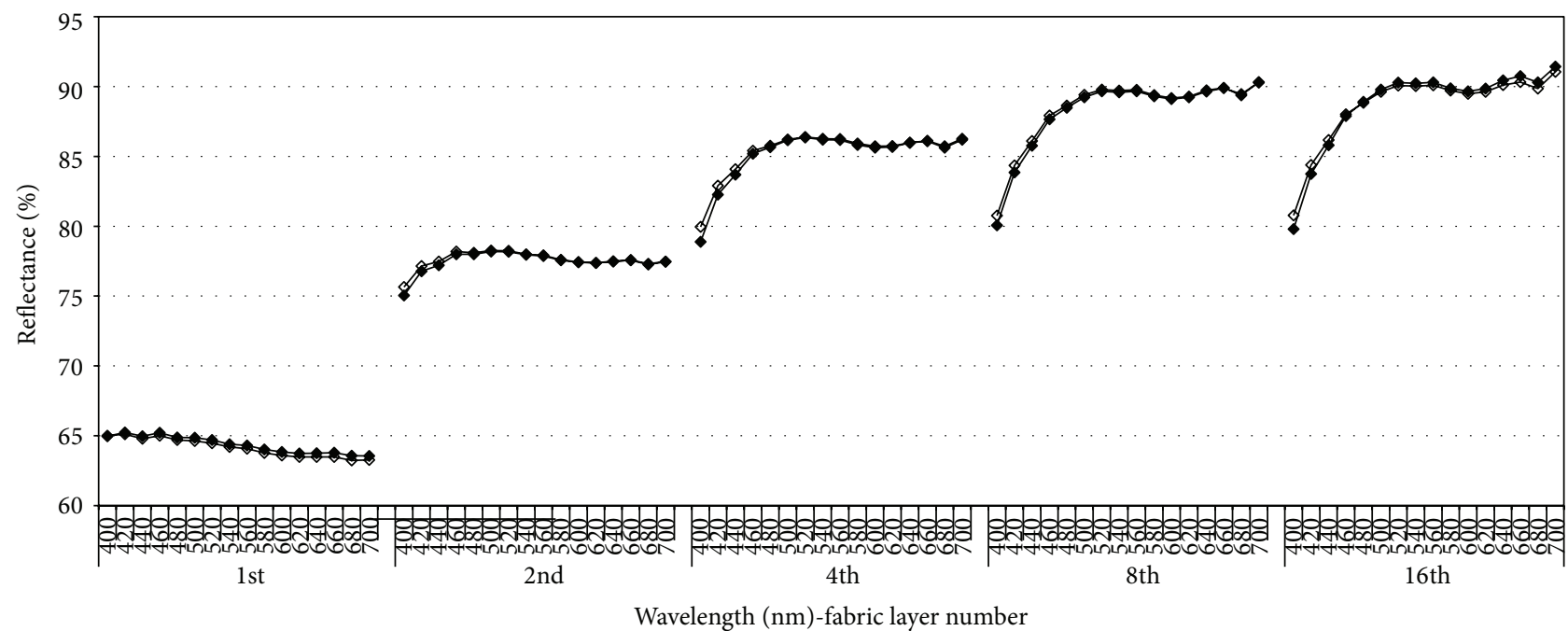

$\rightarrow 15$ threads/cm

$\rightarrow 20$ threads $/ \mathrm{cm}$

FIGURE 4: Percentage reflectances according to weft density (yarn count: 100/144 and weave pattern: plain).

at single fabric layer. In Figure 6, the difference in reflectances decreased as fabric layer numbers increased.

The higher percentage reflectance values of 15-thread weft yarn density fabrics obtained in Figures 1 and 3 at 2 to 16 fabric layers implied that more regular surfaces were obtained in plain and sateen fabrics. This regularity could be a unique result of the combination of yarn density and weave pattern. High yarn densities would be expected to cause more remarkable light reflection than low densities because of the closer settlement of yarns in fabric structure. But this was not observed in Figures 1,3, and 5. The increase of fabric layers in reflectance measurement maximized the effect of yarn densities on fabric percentage reflectance values because distinct differences were obtained between percentage reflectances as the fabric layers increased from 1 to 16 . This could be discussed as the presence of a cross relation between the constructional parameters and percentage reflectances, not a direct one. Percentage reflectance values obtained in Figures 1-6 showed cross relations among weave pattern, yarn density, and filament fineness on light reflection properties of fabric samples.

3.2. Effect of Weave Patterns on Percentage Reflectance. Effects of weave patterns (plain, twill, and sateen) on percentage 


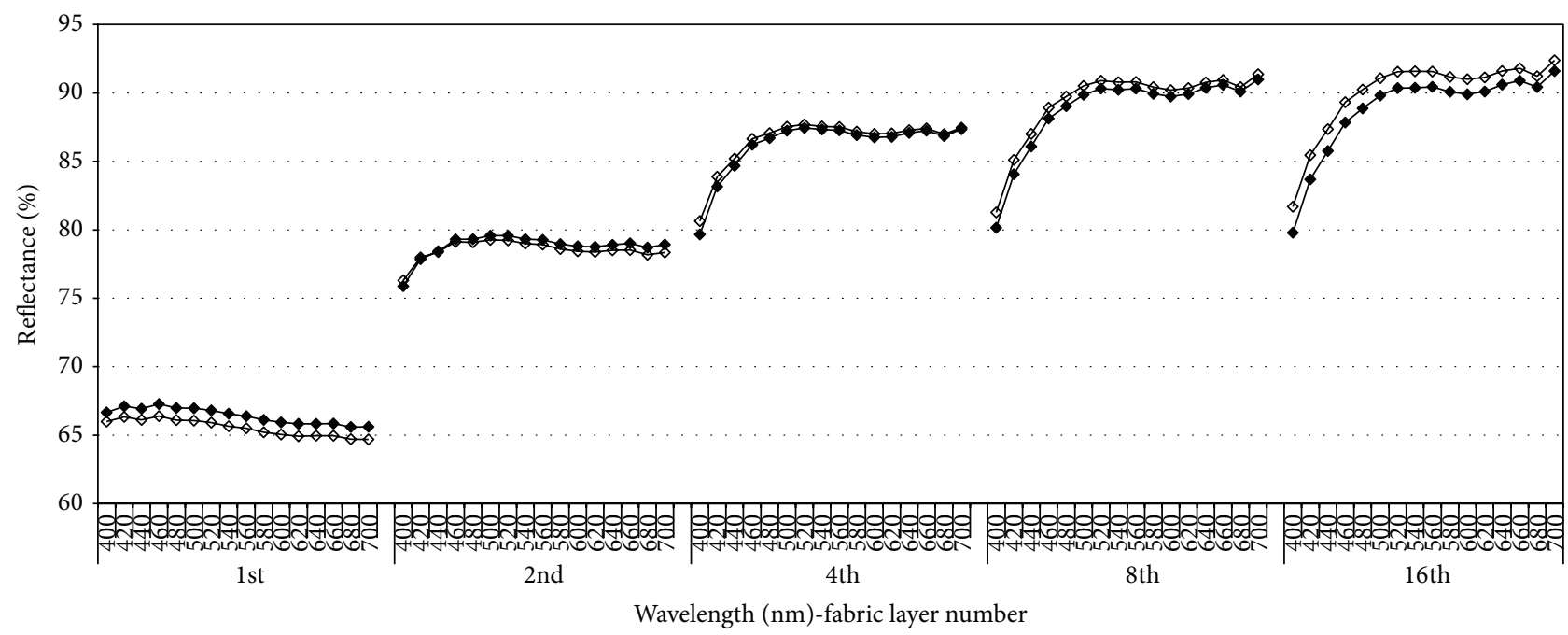

$\rightarrow 15$ threads/cm

$\rightarrow 20$ threads $/ \mathrm{cm}$

Figure 5: Percentage reflectances according to weft density (yarn count: 100/144 and weave pattern: 1/2 twill).

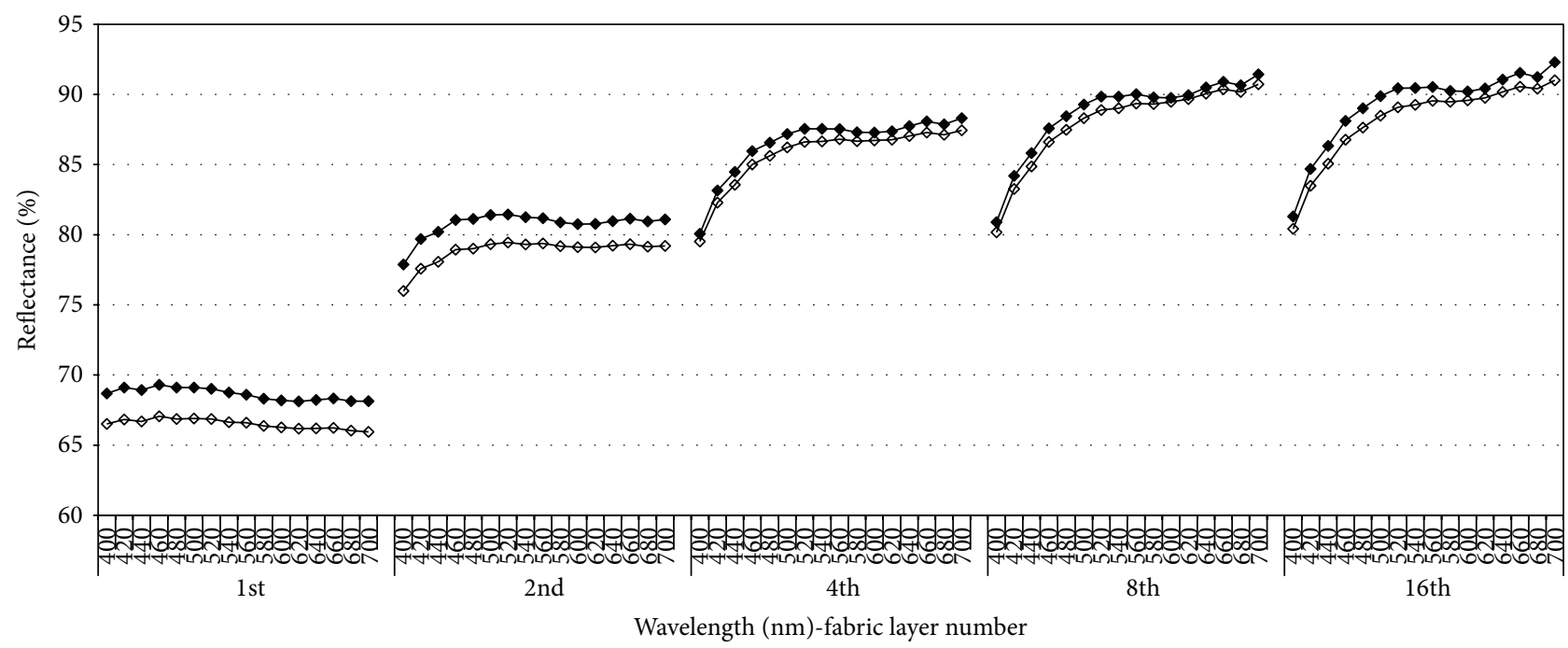

$\rightarrow 15$ threads/cm

$\rightarrow 20$ threads $/ \mathrm{cm}$

FIGURE 6: Percentage reflectances according to weft density (yarn count: 100/144 and weave pattern: 1/5 sateen).

reflectance values of fabric samples were presented in Figures 7 and 8 for 100/36 yarns and in Figures 9 and 10 for 100/144 yarns.

Percentage reflectance values of the fabrics produced from 100/144 yarns (Figures 9 and 10) were considerably higher than percentage reflectance values of the fabrics produced from 100/36 yarns (Figures 7 and 8) especially at the single, 2 , and 4 fabric layers. The reason could be explained considering the different filament fineness of the two yarns. These results were in close relation with the former researches [7, 8]. Microfibers reflect higher proportion of light which falls upon them than conventional fibers do. Also a backscattering effect is obtained in light reflection properties of microfibers. Sateen weave fabrics could be expected to reflect more light especially when woven at high yarn densities. A cross relation was obtained which could be the result of the interaction of different constructional properties because the unique properties of sateen fabrics could not be obtained.

Effect of weave patterns on percentage reflectance values of fabrics was more apparent at single, 2, and 4 fabric layers in Figures 7-8 and in Figures 9-10. The differences which could have been caused from the weave patterns were maximized especially at single fabric layers. 


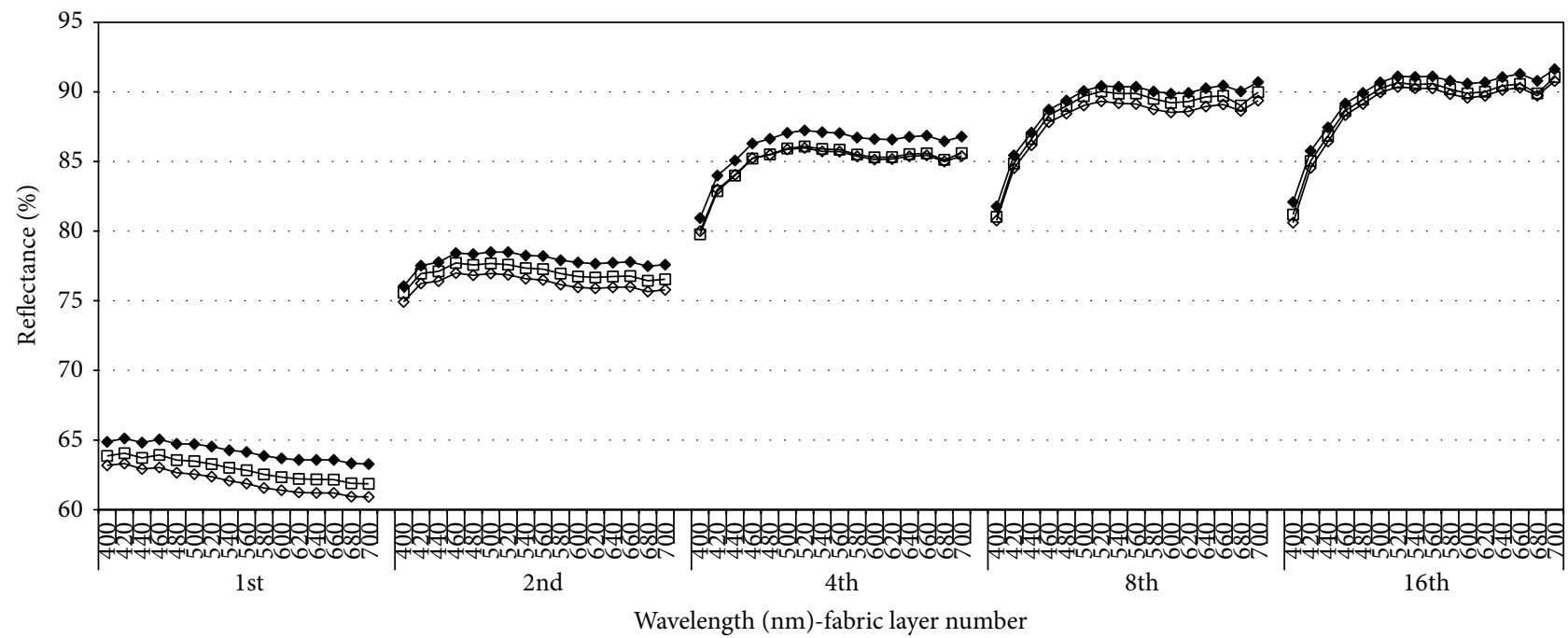

$$
\begin{aligned}
& \rightarrow \text { Plain } \\
& \rightarrow 1 / 2 \text { twill } \\
& \rightarrow-1 / 5 \text { sateen }
\end{aligned}
$$

FIGURE 7: Percentage reflectances according to weave pattern (yarn count: 100/36 and weft density: 15 threads/cm).

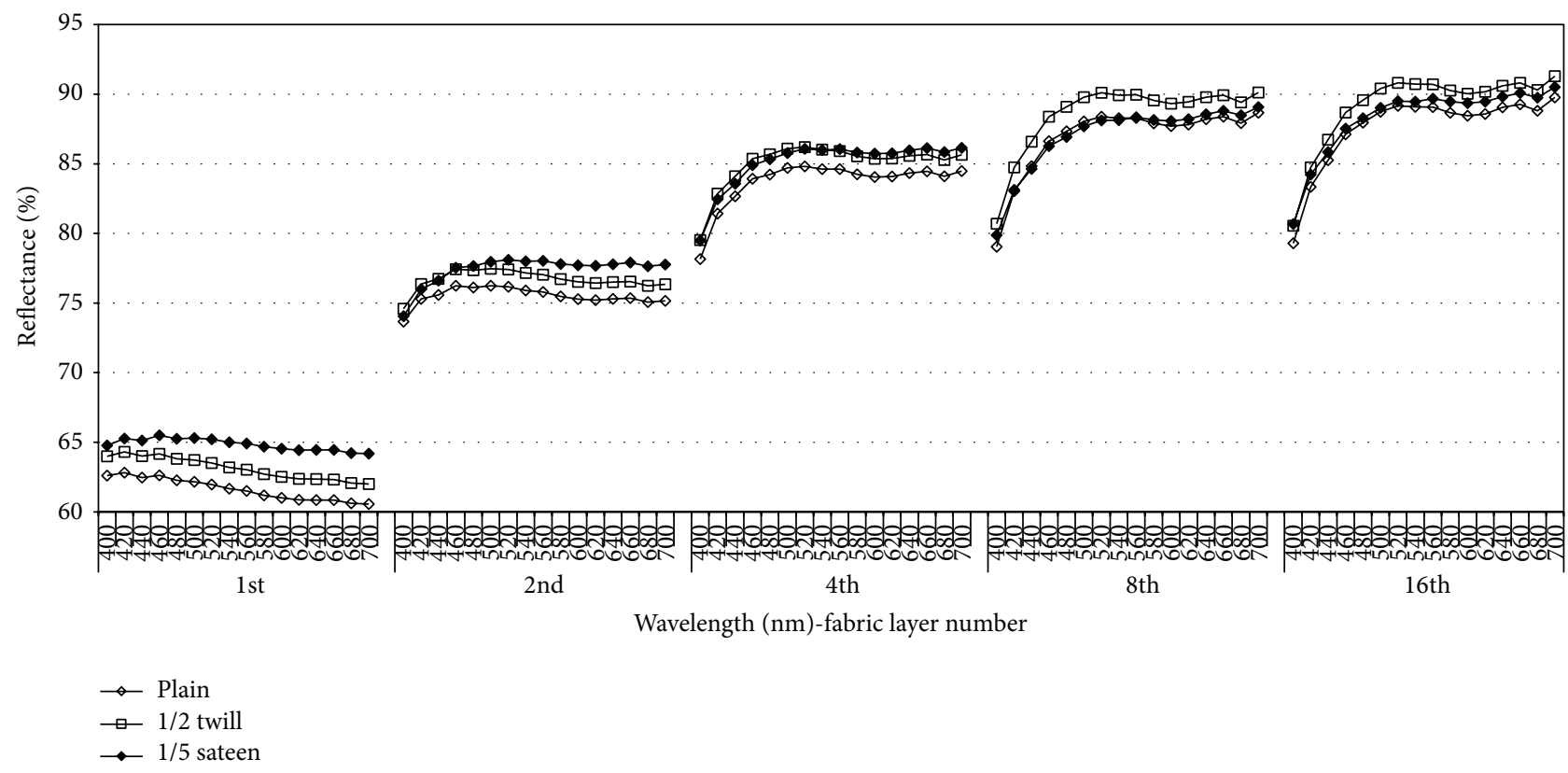

FIGURE 8: Percentage reflectances according to weave pattern (yarn count: 100/36 and weft density: 20 threads/cm).

Intrinsic reflectances of the fabric samples obtained at single, 2 , and 4 fabric layers in Figures 7-10 revealed the wellknown and established reflectance behaviors of the plain, twill, and sateen fabrics and microfiber yarns.

Effect of weave patterns on percentage reflectance values was found to be dependent on the filament fineness and yarn density especially at single, 2 , and 4 fabric layers. The fabrics produced from conventional fibers and microfibers began to be similar to each other as the fabric layers increased in terms of fabric percentage reflectance values. An overall consideration of Figures 7-10 showed that the effect of weave patterns on percentage reflectance values changed mainly with the fabric layer numbers.

3.3. Effect of Filament Fineness on Percentage Reflectance. Effects of filament fineness on percentage reflectance values 


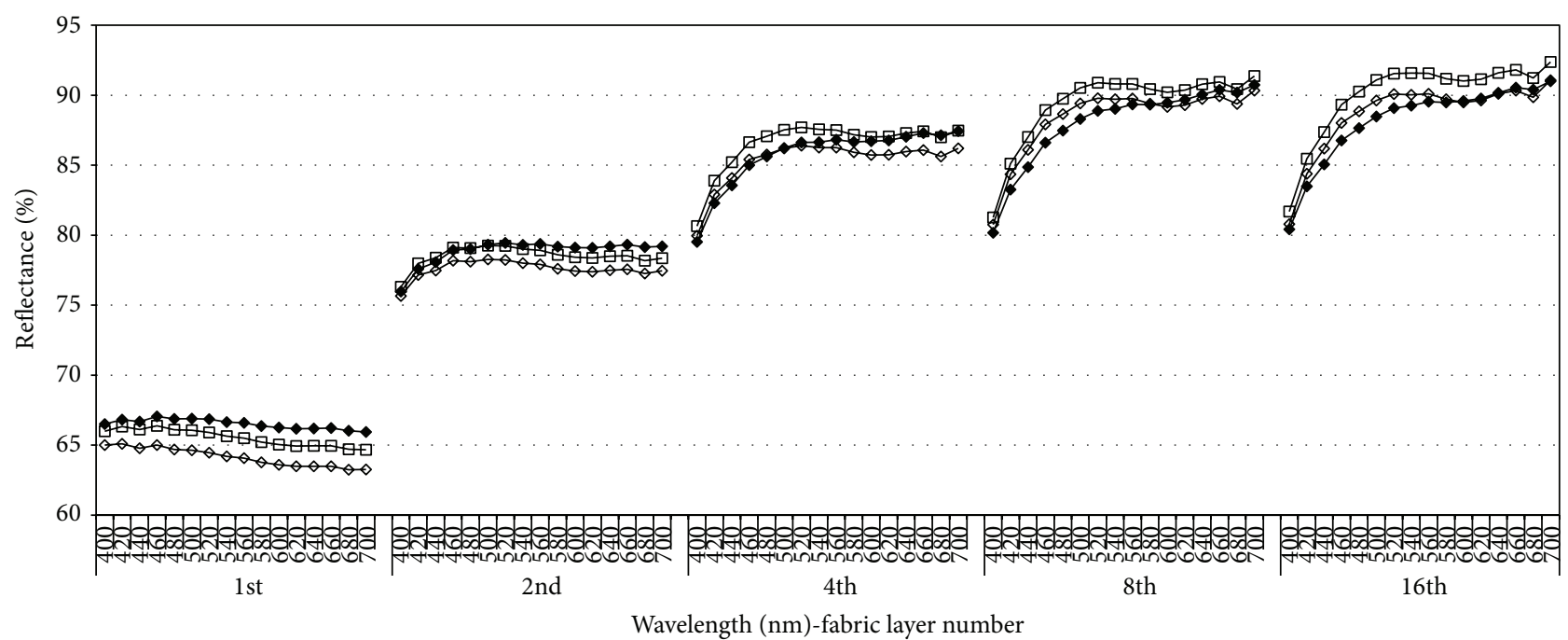

$$
\begin{aligned}
& \rightarrow \text { Plain } \\
& \rightarrow 1 / 2 \text { twill } \\
& \rightarrow-1 / 5 \text { sateen }
\end{aligned}
$$

FIGURE 9: Percentage reflectances according to weave pattern (yarn count: 100/144 and weft density: 15 threads/cm).

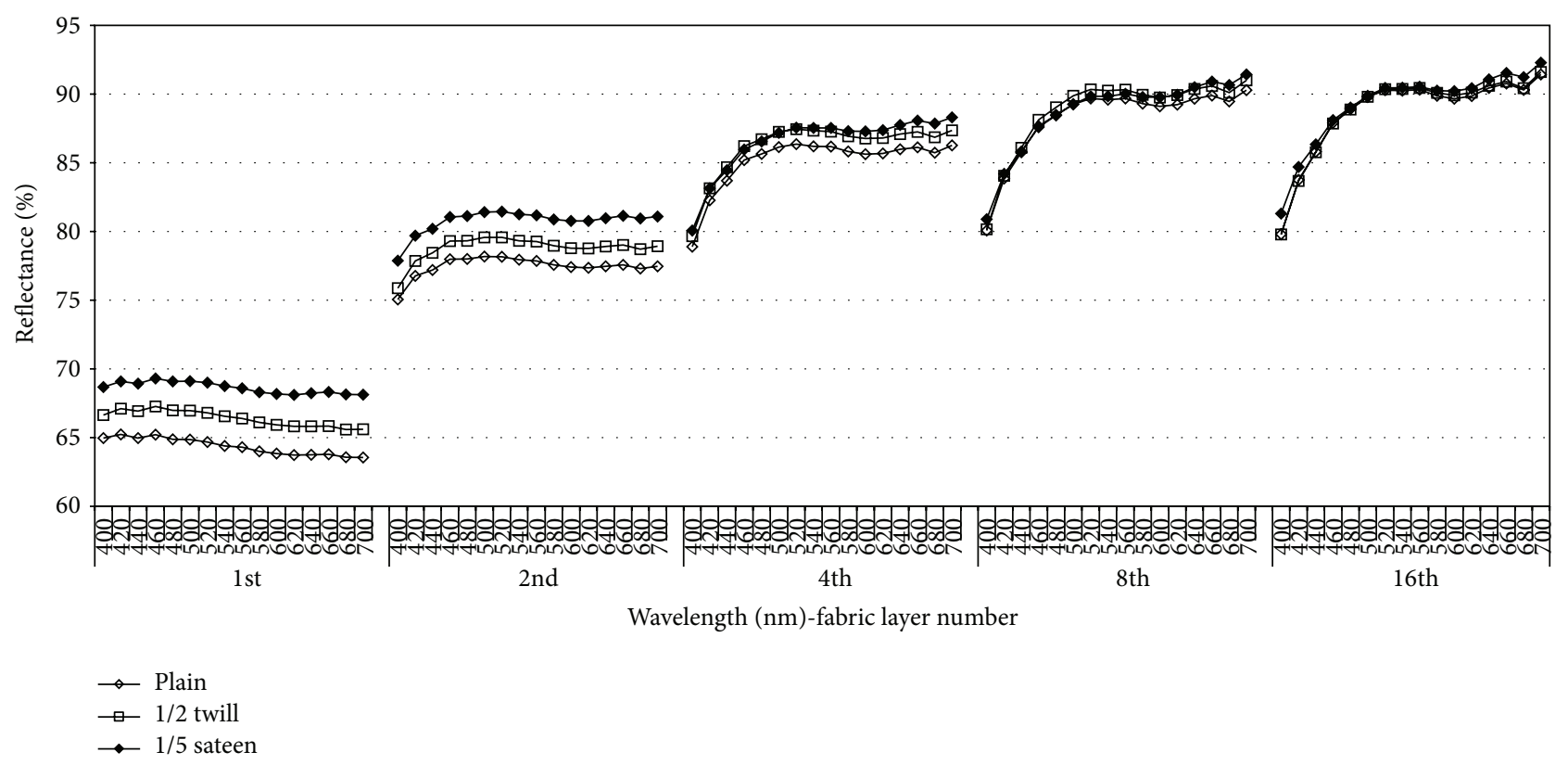

FIGURE 10: Percentage reflectances according to weave pattern (yarn count: 100/144 and weft density: 20 threads/cm).

of plain, twill, and sateen patterned fabrics were presented in Figures 11-16 for the two different weft yarn densities (15 and 20 threads/cm).

Percentage reflectance values presented in Figures 11-16 differed according to filament fineness when weave patterns were considered. Effect of filament fineness on reflectance values disappeared at plain fabrics as fabric layers increased (Figures 11 and 12). However, percentage reflectance values presented exact differences at twill and sateen weaves as fabric layers increased. Percentage reflectance values obtained at samples woven with 100/144 yarns were always higher than those of fabrics woven with 100/36 yarns in Figures 13, 15, and 16, except for 16 layers in Figure 14. In Figures 11 and 12, the increase of fabric layers hindered the effect of filament fineness on percentage reflectance values in plain fabrics. Percentage reflectance values became close to each other as 


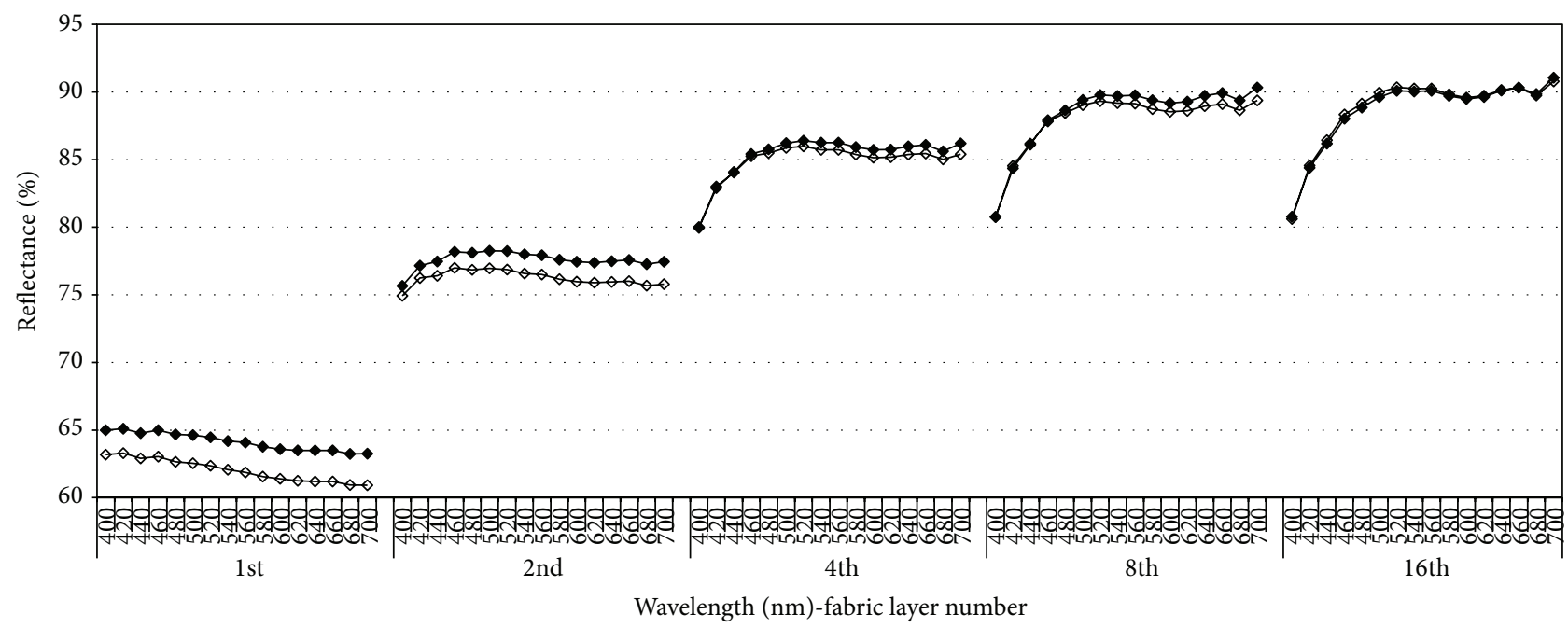

$\rightarrow$ 100/36 denier/filament

$\rightarrow$ 100/144 denier/filament

FIGURE 11: Percentage reflectances of fabrics according to filament numbers (weft density: 15 threads/cm and weave pattern: plain).

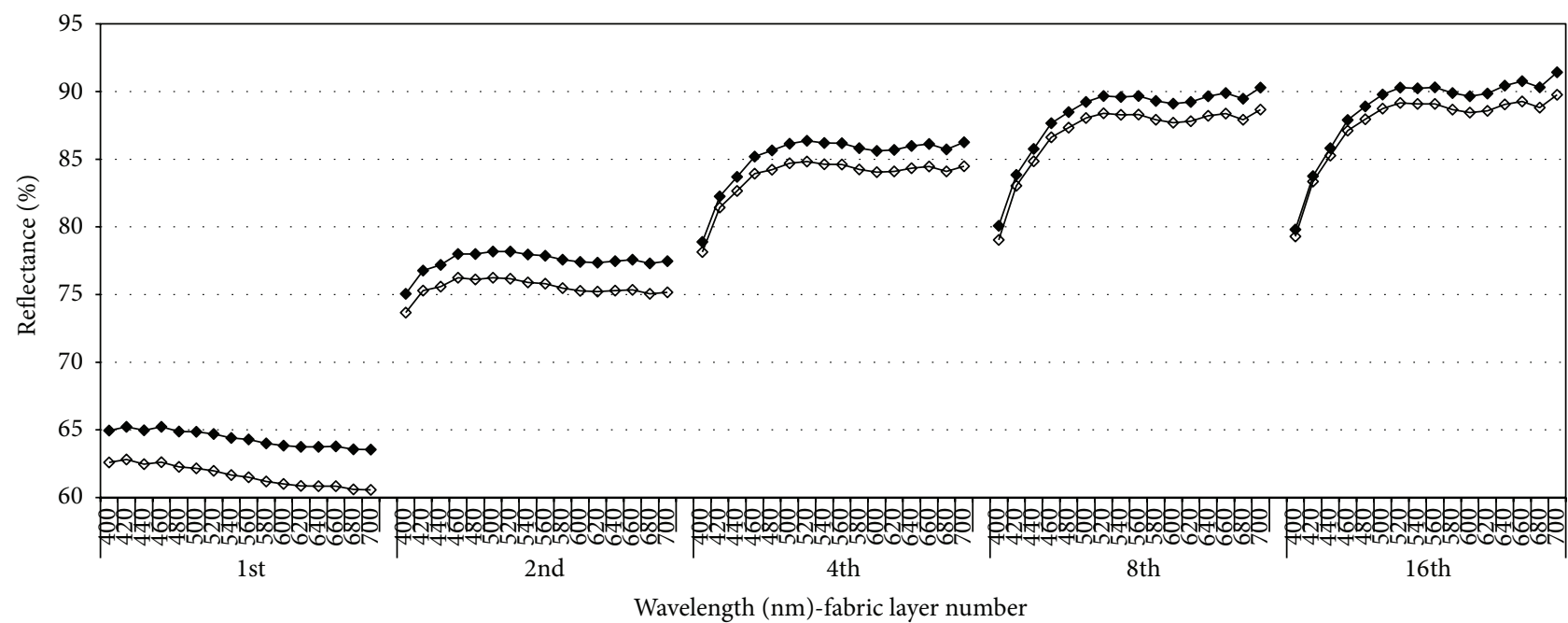

$\rightarrow 100 / 36$ denier/filament

$\rightarrow$ 100/144 denier/filament

FIGURE 12: Percentage reflectances of fabrics according to filament numbers (weft density: 20 threads/cm and weave pattern: plain).

fabric layer numbers increased. Almost the same percentage reflectance values were obtained at the 16 times layered fabrics in Figures 11 and 12.

Percentage reflectance values obtained at single fabric layer in Figures 15 and 16 were considerably higher than the ones in Figures 11-14. However, percentage reflectance values obtained at 15-thread weft yarn density (Figure 15) were slightly higher than the ones obtained at 20-thread weft yarn density (Figure 16). Although both figures presented the results obtained with sateen weaves, there were considerable cross results within the figures.
When all the figures of percentage reflectance values were considered, it could be stated that direct relations could not be obtained among constructional parameters of fabrics and percentage reflectances, but cross relations.

3.4. Statistical Analysis. Statistical assessments and corresponding ANOVA (Analysis of Variance) (COSTAT Software) results were presented in Tables 2 and 3. Percentage reflectance values of fabric samples according to layer numbers in connection with the factors of weft density, filament number, and weave pattern were presented in Table 2. 


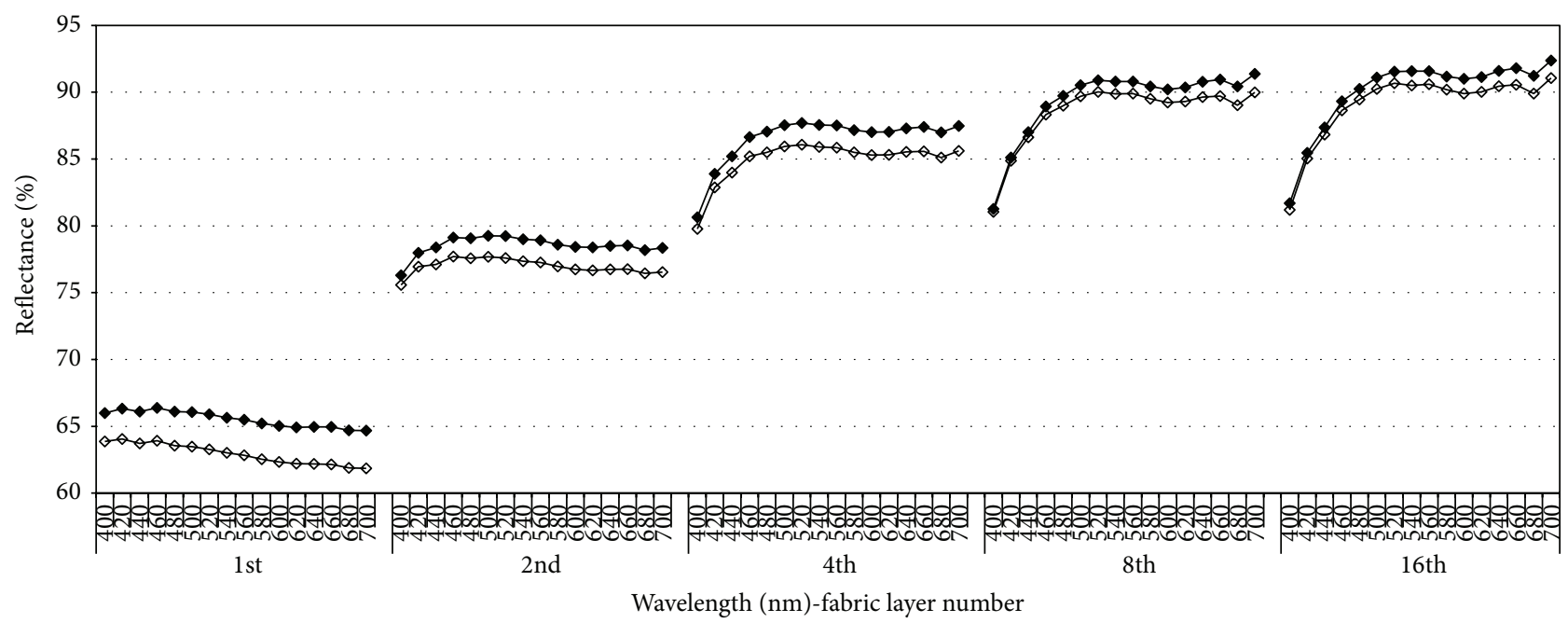

$\rightarrow$ 100/36 denier/filament

$\rightarrow$ 100/144 denier/filament

FIGURE 13: Percentage reflectances of fabrics according to filament numbers (weft density: 15 threads/cm and weave pattern 1/2 twill).

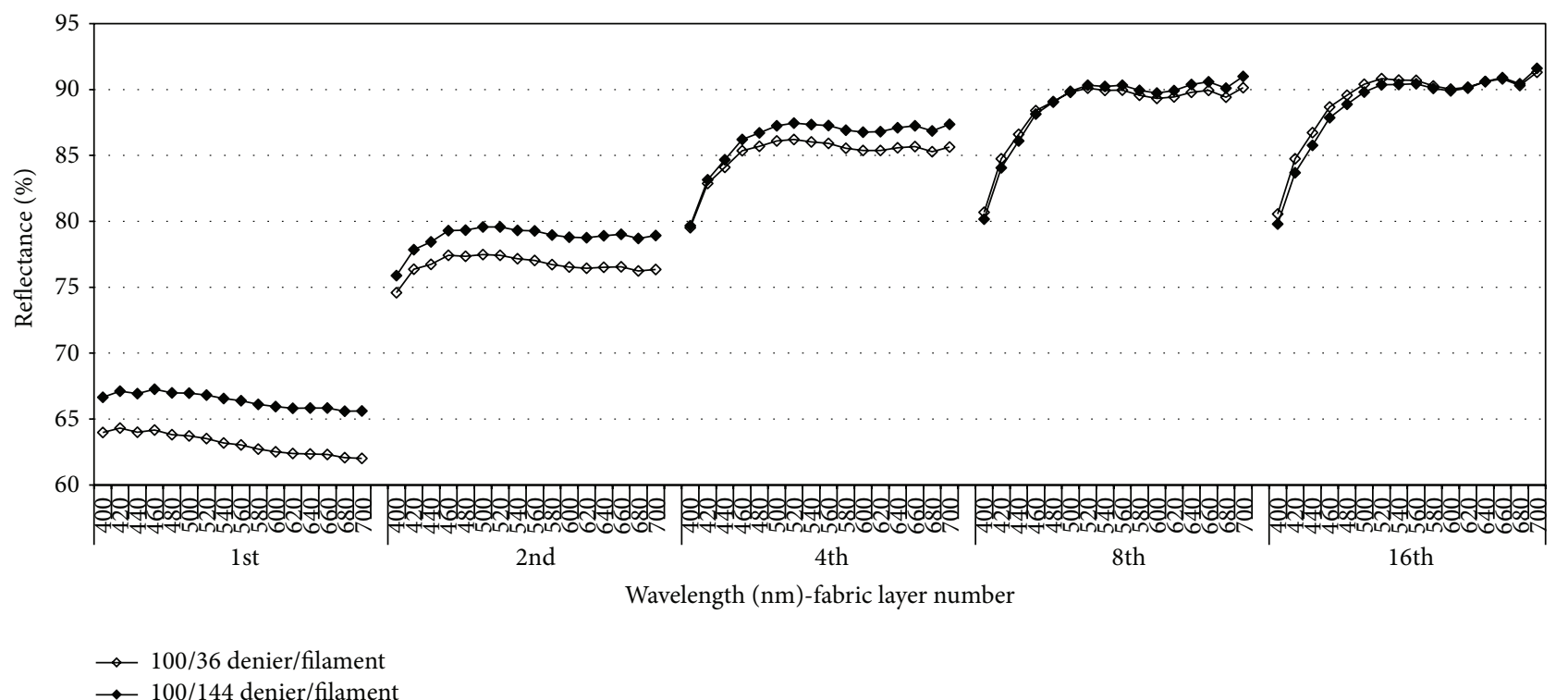

FIgURE 14: Percentage reflectances of fabrics according to filament numbers (weft density: 20 threads/cm and weave pattern: $1 / 2$ twill).

The ranks were presented from the highest reflectance values to the lowest ones. Fabric samples which had the highest percentage reflectance values changed in connection with the fabric layer numbers. Table 2 revealed the cross relations among the fabric constructional properties and percentage reflectance values from the viewpoint of statistical analysis.

According to ANOVA analysis presented in Table 2, fabrics woven with microfibers (100/144 yarns) had higher percentage reflectance values than the ones woven with conventional fibers (100/36 yarns). This was an expected result because microfibers reflect incident light better than conventional fibers as a result of their dimensional characteristics
$[7,8]$. The backscattering effect of microfibers also plays an important role in reflectance behavior of fabrics including these fibers. Except single fabric layer number, percentage reflectance values obtained with 15-thread weft yarn density were higher than the ones obtained with 20-thread weft yarn density. This was an unexpected result. The low reflectance results of 20-thread weft yarn density could be ascribed to the light-trap phenomenon. The high reflectance results of 15thread weft yarn density implied that a more regular fabric surface was formed. Except 8 and 16 fabric layers, sateen fabrics had the highest percentage reflectance values. In 8 and 16 fabric layers, twill fabrics had the highest percentage 


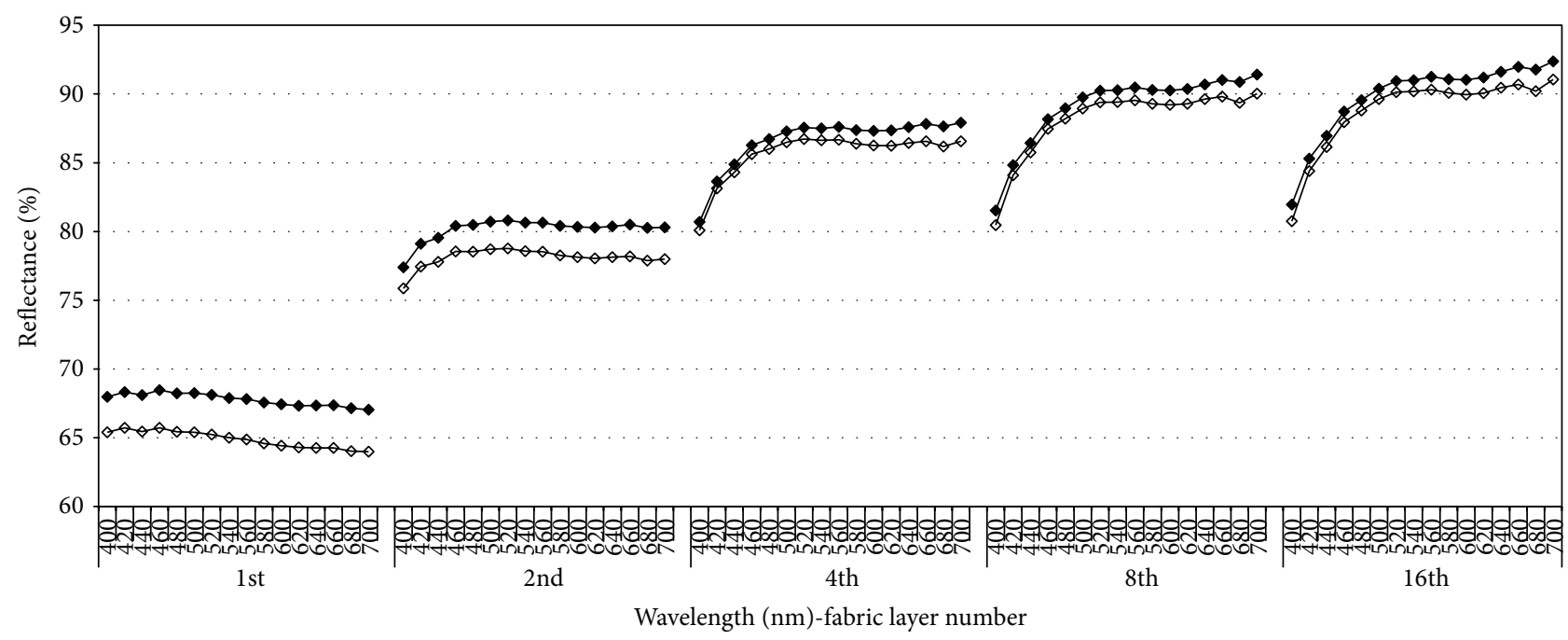

$\rightarrow$ 100/36 denier/filament

$\rightarrow$ 100/144 denier/filament

FIGURE 15: Percentage reflectances of fabrics according to filament numbers (weft density: 15 threads/cm and weave pattern: 1/5 sateen).

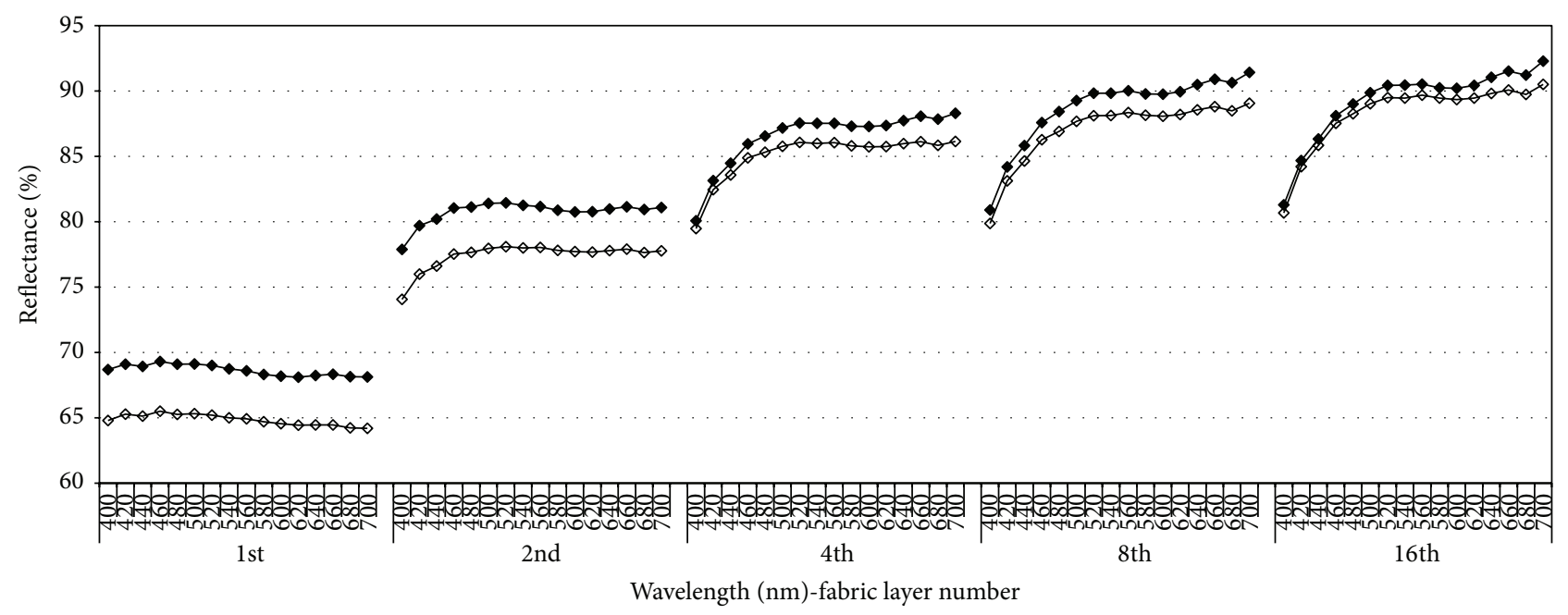

$\rightarrow 100 / 36$ denier/filament

$\rightarrow$ 100/144 denier/filament

FIGURE 16: Percentage reflectances of fabrics according to filament numbers (weft density: 20 threads/cm and weave pattern: 1/5 sateen).

reflectance values. The higher percentage reflectance values of twill fabrics were another unexpected result because sateen fabrics are well known with their glossy appearance.

The higher percentage reflectance values of twill weaves accompanied with the higher percentage reflectance values of 15-thread weft yarn density implied that there were cross relations between fabric constructional properties and percentage reflectance values.

ANOVA results of percentage reflectance values according to fabric layer numbers were presented in Table 3. The highest reflectance values were obtained at the measurement with 16 fabric layers. It was obvious that percentage reflectance values increased as number of fabric layers increased under illumination. Number of fabric layers for reflectance measurement of white textiles must be at least 8 layers. But depending on filament fineness, yarn density, and weave pattern, number of layers must be 16 when very fine yarns, for example, microfibers, were considered. Also the percentage reflectance curves in the figures showed that there were significant differences between the values obtained up to eight fabric layers while the differences were much less between the values obtained at eight and sixteen fabric layers.

Yarn density played an important role on percentage reflectance values when the weave patterns changed from 
TABLE 2: ANOVA results according to fabric constructional parameters.

\begin{tabular}{|c|c|c|c|}
\hline Fabric layer number & Factors & Treatment & $\begin{array}{c}\text { Fabric reflectance } \\
{ }^{*} \text { Rank }\end{array}$ \\
\hline \multirow{7}{*}{ 1th } & \multirow{2}{*}{$\begin{array}{l}\text { Weft density } \\
\quad(1 / \mathrm{cm})\end{array}$} & $1(15)$ & 2 \\
\hline & & $2(20)$ & 1 \\
\hline & \multirow{3}{*}{$\begin{array}{c}\text { Filament number } \\
\text { (denier/filament number) }\end{array}$} & $1(100 / 36)$ & 2 \\
\hline & & $2(100 / 144)$ & 1 \\
\hline & & 1 (plain) & 3 \\
\hline & \multirow[t]{2}{*}{ Weave pattern } & 2 (twill 1/2) & 2 \\
\hline & & 3 (sateen $1 / 5)$ & 1 \\
\hline \multirow{7}{*}{ 2nd } & \multirow{2}{*}{$\begin{array}{l}\text { Weft density } \\
\quad(1 / \mathrm{cm})\end{array}$} & $1(15)$ & 1 \\
\hline & & $2(20)$ & 2 \\
\hline & \multirow{3}{*}{$\begin{array}{c}\text { Filament number } \\
\text { (denier/filament number) }\end{array}$} & $1(100 / 36)$ & 2 \\
\hline & & $2(100 / 144)$ & 1 \\
\hline & & 1 (plain) & 3 \\
\hline & \multirow[t]{2}{*}{ Weave pattern } & $2($ twill 1/2) & 2 \\
\hline & & 3 (sateen $1 / 5$ ) & 1 \\
\hline \multirow{7}{*}{4 th } & \multirow{2}{*}{$\begin{array}{l}\text { Weft density } \\
\qquad(1 / \mathrm{cm})\end{array}$} & $1(15)$ & 1 \\
\hline & & $2(20)$ & 2 \\
\hline & \multirow{3}{*}{$\begin{array}{c}\text { Filament number } \\
\text { (denier/filament number) }\end{array}$} & $1(100 / 36)$ & 2 \\
\hline & & $2(100 / 144)$ & 1 \\
\hline & & 1 (plain) & 3 \\
\hline & \multirow[t]{2}{*}{ Weave pattern } & 2 (twill 1/2) & 2 \\
\hline & & 3 (sateen 1/5) & 1 \\
\hline \multirow{7}{*}{ 8th } & \multirow{2}{*}{$\begin{array}{l}\text { Weft density } \\
(1 / \mathrm{cm})\end{array}$} & $1(15)$ & 1 \\
\hline & & $2(20)$ & 2 \\
\hline & \multirow{3}{*}{$\begin{array}{c}\text { Filament number } \\
\text { (denier/filament number) }\end{array}$} & $1(100 / 36)$ & 2 \\
\hline & & $2(100 / 144)$ & 1 \\
\hline & & 1 (plain) & 2 \\
\hline & \multirow[t]{2}{*}{ Weave pattern } & 2 (twill 1/2) & 3 \\
\hline & & 3 (sateen $1 / 5$ ) & 1 \\
\hline \multirow{7}{*}{ 16th } & \multirow{2}{*}{$\begin{array}{l}\text { Weft density } \\
(1 / \mathrm{cm})\end{array}$} & $1(15)$ & 1 \\
\hline & & $2(20)$ & 2 \\
\hline & \multirow{3}{*}{$\begin{array}{c}\text { Filament number } \\
\text { (denier/filament number) }\end{array}$} & $1(100 / 36)$ & 2 \\
\hline & & $2(100 / 144)$ & 1 \\
\hline & & 1 (plain) & 2 \\
\hline & \multirow[t]{2}{*}{ Weave pattern } & 2 (twill 1/2) & 3 \\
\hline & & 3 (sateen $1 / 5)$ & 1 \\
\hline
\end{tabular}

${ }^{*}$ The rank is presented from the highest percentage reflectance to the lowest percentage reflectance.

plain to sateen. Filament fineness played an important role on percentage reflectance values when number of fabric layers and weave patterns changed.

Reflectance behavior of different fabrics became similar to each other as the number of layers increased. Also, the same discussion could be made for the fabrics with plain weave, for the fabrics with low weft density, and for the fabric woven with conventional fibers. The light-trap phenomenon was also observed in relation with the fabric layers [6]. Loose structures with small layer numbers (1, 2, and 4 layers) caused most of the incident light to be captured by the achromatic black background and by interfabric holes. Also, the measured reflectance values decreased in fabrics with high yarn density as the layer numbers increased. This could be also attributed to light-trap phenomenon.

\section{Conclusions}

Effects of yarn densities, weave patterns, and filament fineness on percentage reflectance values of white polyester fabric 
TABLE 3: ANOVA results according to fabric layer number.

\begin{tabular}{lcc}
\hline Factors & Treatment & $\begin{array}{c}\text { Fabric reflectance } \\
{ }^{*} \text { Rank }\end{array}$ \\
\hline & $1(1 \mathrm{th})$ & 5 \\
Fabric layer number & $2(2 \mathrm{nd})$ & 4 \\
& $3(4 \mathrm{th})$ & 3 \\
& $4(8 \mathrm{th})$ & 2 \\
$5(16 \mathrm{th})$ & 1 \\
\hline
\end{tabular}

* The rank is presented from the highest reflectance to the lowest reflectance.

samples were reported in accordance with fabric layer numbers. Percentage reflectance results showed that the inherited properties of white fabric samples were lost when they were layered more than eight times for reflectance measurement.

Constructional parameters affected the measured percentage reflectance values at single, 2 , and 4 fabric layers at most. The differences in constructional parameters lost their effects on percentage reflectance values when fabric layer numbers increased up to 16 layers. Fabric constructional parameters showed cross relations with percentage reflectance values. Percentage reflectance values were directed in different manners by constructional parameters and it became impossible to make an exact conclusion on the single effects of these parameters on reflectance. The cross relations were also revealed by statistical results. Change of percentage reflectance values with constructional properties implied that the intrinsic reflectance properties of fabric structures must be measured at single fabric layer in order to avoid the cross relations. Considering the results which were presented in this paper and in the former papers $[1,2,6-9,14]$, the usage of the term of "appearance measurement" could be proposed instead of "color or reflectance measurement" to consider the reflectance measurements of the white and patterned fabric structures.

Textile fabrics have constructional characteristics changing from noncompact structures to compact ones. For that reason, reflectance behaviors of fabric samples depended on constructional factors (yarn density, yarn filament numbers, weave pattern, etc.) which directed the compactness of structures. The optimum layer number suitable for each fabric could be determined in the beginning of measurements. The light-trap phenomenon was observed both in fabrics with loose structures during measurement at low fabric layers and in fabrics with compact structures during measurement at high fabric layers. The determination of suitable fabric layer for reflectance measurement should be made prior to the measurement cycles to perform a better application regarding the fabric compactness.

\section{Conflict of Interests}

The authors do not have any stake in Macbeth Kollmorgen (former) or AATCC and their names appear in the paper purely in coincidental and academic nature. Their reference is made to indicate standard equipment and test method made use of in this work and in no way it advocates these brands.

\section{References}

[1] R. D. Lozano, "A new approach to appearance characterization," Color Research \& Application, vol. 31, no. 3, pp. 164-167, 2006.

[2] J. L. Caivano, "Cesia : a system of v isual signs complementing color," Color Research and Application, vol. 16, no. 4, pp. 258$268,1991$.

[3] B. Rigg, "Colorimetry and the CIE system," in Colour Physics for Industry, R. McDonald, Ed., Society of Dyers and Colourists, Bradford, UK, 1987.

[4] R. Berns, Billmeyer and Saltzmann's Principles of Color Technology, John Wiley \& Sons, New York, NY, USA, 2000.

[5] R. S. Hunter, The Measurement of Appearance, John Wiley \& Sons, New York, NY, USA, 1975.

[6] D. Steen and D. Dupont, "Control of structured white textiles," Coloration Technology, vol. 119, no. 4, pp. 205-211, 2003.

[7] H. Kobsa, B. Rubin, S. M. Shearer, and E. M. Schulz, "Using optical ray tracing to explain the reduced dye yield of microdenier yarns," Textile Research Journal, vol. 63, no. 8, pp. 475-479, 1993.

[8] B. Rubin, H. Kobsa, and S. M. Shearer, "Modelling the dependence of fabric reflectance on denier per filament," Textile Research Journal, vol. 64, no. 11, pp. 685-689, 1994.

[9] M. Akgun, B. Becerir, and H. R. Alpay, "Assessing the relationship among fabric constructional parameters, fractional reflectances and cover factors of polyester fabrics by experimental and mathematical methods," Fibers and Polymers, vol. 11, no. 2, pp. 291-302, 2010.

[10] B. Becerir and M. A. Iskender, "Comparison of some process components of polyester microfibre dyeing by using mathematical and experimental methods," Fibers and Polymers, vol. 5, no. 4, pp. 309-315, 2004.

[11] B. Becerir, "A novel approach for estimating the relation between K/S value and dye uptake in reactive dyeing of cotton fabrics," Fibers and Polymers, vol. 6, no. 3, pp. 224-228, 2005.

[12] B. Becerir, "Assessment of the results of different color difference formulae under different illuminants by wash fastness tests," Fibers and Polymers, vol. 12, no. 7, pp. 946-956, 2011.

[13] American Association of Textile Chemists and Colorists, AATCC Technical Manual, vol. 74, AATCC, Research Triangle Park, NC, USA, 2005.

[14] M. Akgun, B. Becerir, and H. R. Alpay, "Abrasion of polyester fabrics containing staple weft yarns: color strength and color difference values," AATCC Review, vol. 6, no. 3, pp. 40-43, 2006. 

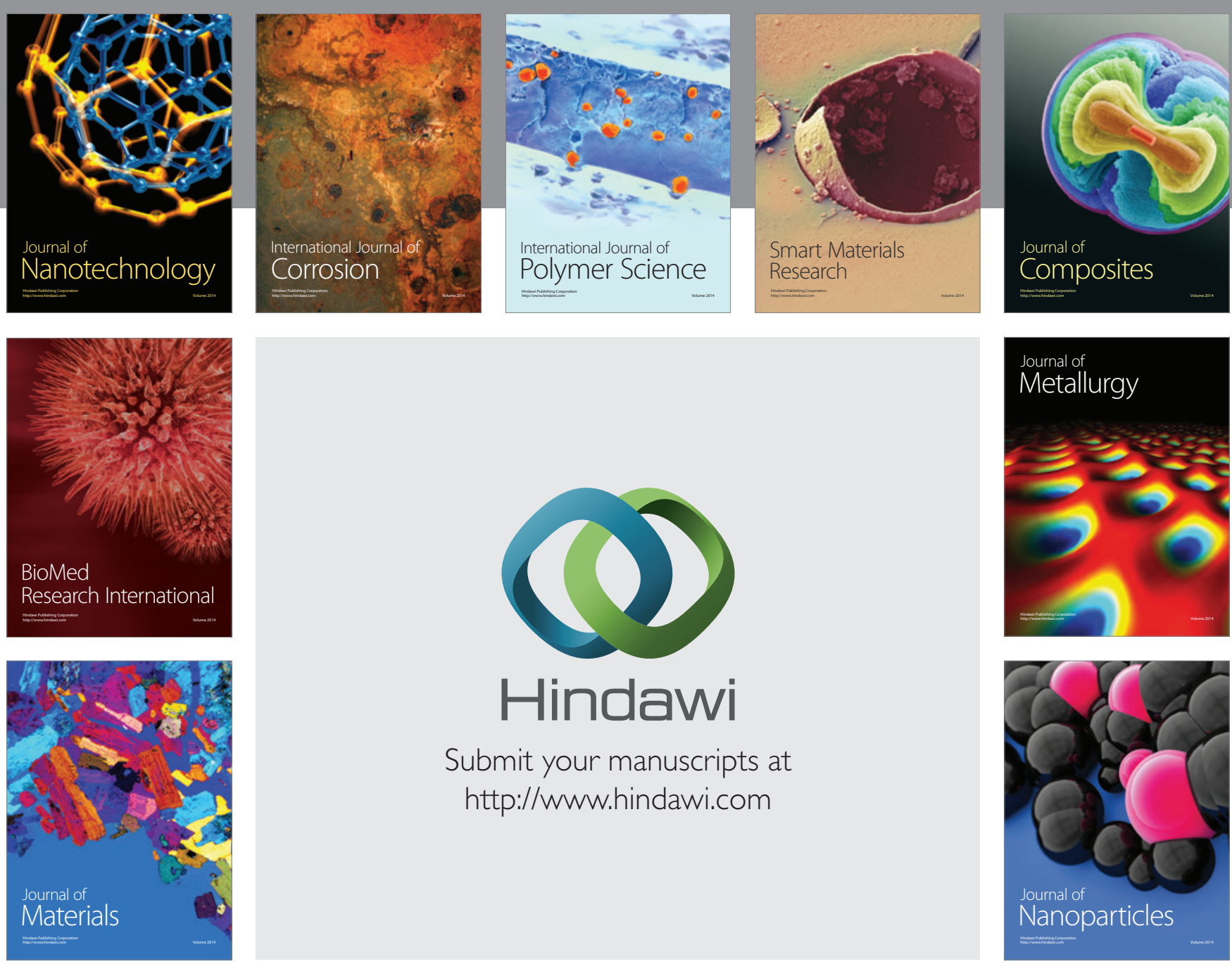

Submit your manuscripts at http://www.hindawi.com
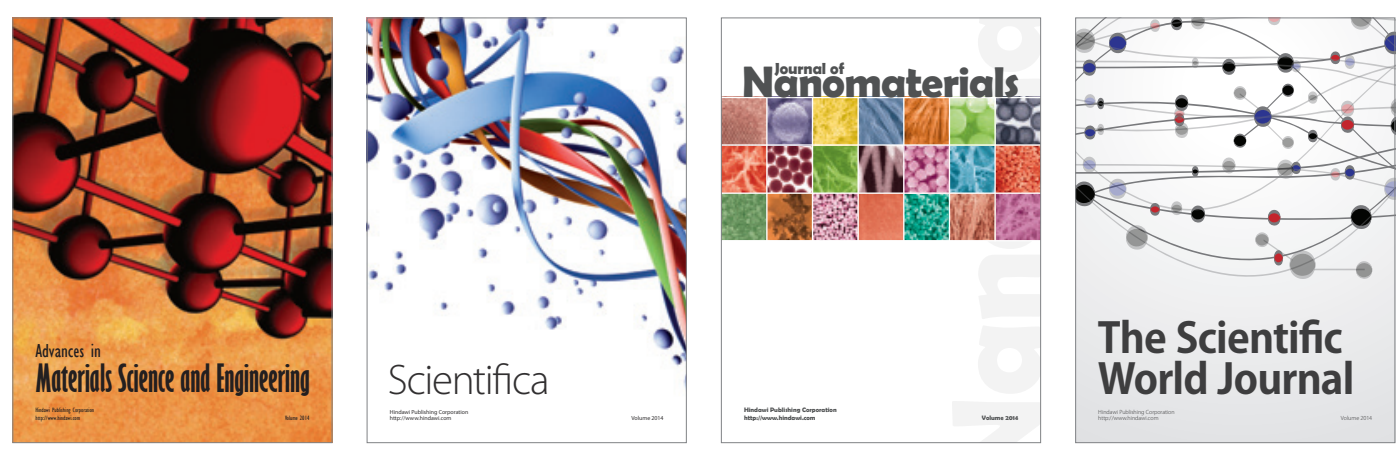

\section{The Scientific World Journal}
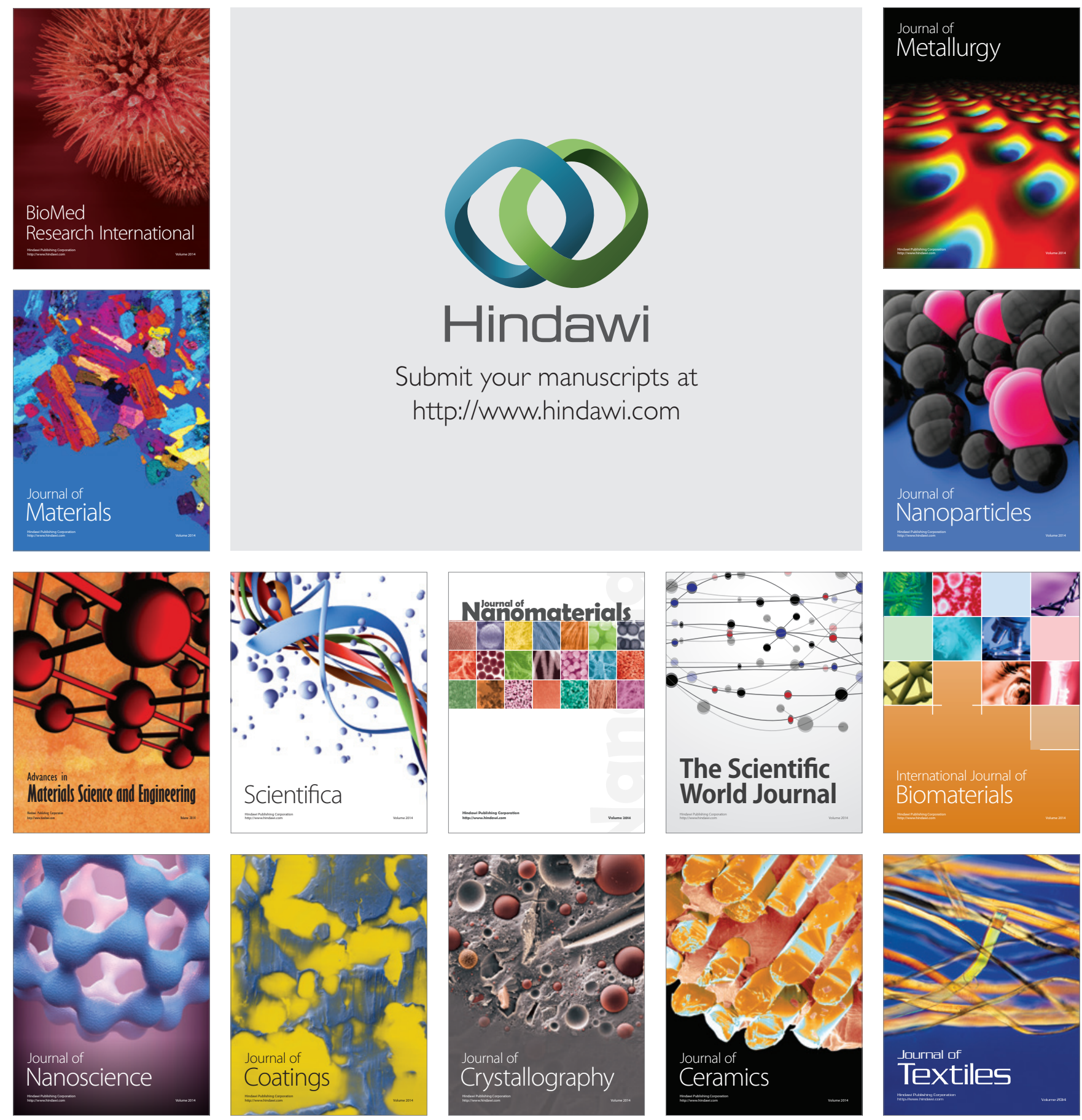